\title{
Student perception of the educational environment in an evolving medical school in Sri Lanka
}

\author{
Ranaweera $\mathrm{SMKA}^{1} *$, Nanayakkara NGGCS ${ }^{2}$, Sanjeewa WA ${ }^{1}$, Perera HTC ${ }^{1}$, \\ Warnasekara YPJN ${ }^{3}$, Koralegedara KIS ${ }^{1}$, Paththinige $\mathrm{CS}^{1}$ \\ ${ }^{\prime}$ Department of Anatomy, Faculty of Medicine and Allied Sciences, Rajarata University \\ of Sri Lanka. \\ ${ }^{2}$ Department of Forensic Medicine, Faculty of Medicine, University of Peradeniya. \\ ${ }^{3}$ Department of Community Medicine, Faculty of Medicine and Allied Sciences, \\ Rajarata University of Sri Lanka. \\ *kalharianuradha@gmail.com
}

Educational environment is crucial in determining students' learning and the success of an educational program. This study assessed the students' perception regarding the educational environment in the Faculty of Medicine and Allied Sciences, Rajarata University of Sri Lanka (FMAS, RUSL). Dundee Ready Education Environment Measure (DREEM) was administered online to all undergraduates of FMAS, RUSL maintaining anonymity. Results were analyzed using SPSS-20, descriptive statistics and Mann-Whitney-U test based on DREEM guidelines. The study was approved by Ethic Review Committee, FMAS, RUSL. Total of 681 students $(63.1 \%)$ responded [Preclinical 448 (65.8\%); Senior (paraclinical and clinical) 233 (34.2\%)]. The majority $(67.7 \%)$ were females. Overall mean score was $139.6 \pm 28.5(69.8 \%)$ indicating 'more positive than negative' perception. Mean scores for all sub-domains were one grade below the best. The highest score was related to perception of learning (75.8\%) and the lowest scores to atmosphere $(66.7 \%)$ and social selfperception (66.8\%). Items with the highest scores were the knowledge (3.53) and preparedness (3.42) of teachers and the lowest score was related to the ability to memorize (2.07). Academic self-perception was significantly higher among males (Mann-Whitney-U 40974.0, $\mathrm{p}<0.001$ ), and no significant gender difference was observed in other sub-domains. Perception of educational environment was significantly more positive among pre-clinical students $(\mathrm{p}<0.05)$ in all sub-domains, compared to senior students. Of the 50 items, 37 showed significant difference between preclinical and senior students $(\mathrm{P}<0.05)$, and scores of 35 items were higher among pre-clinical students. Majority of undergraduates of FMAS, RUSL perceived educational environment positively. This study has identified areas requiring improvement for the success of educational programme of FMAS, RUSL. 